\title{
A mechanism for the hypocholesterolaemic activity of saponins
}

\author{
BY G. S. SIDHU AND D. G. OAKENFULL \\ CSIRO Division of Food Research, PO Box 52, North Ryde, \\ NSW 2113, Australia
}

(Received 10 January 1986 - Accepted 14 January 1986)

1. Saponins are steroid or triterpene glycosides which occur in a number of important food plants, including such staples as soya beans (Glycine max) and chickpeas (Cicer arietinum). They are known to be hypocholesterolaemic.

2. Some saponins form an insoluble complex with cholesterol which prevents its absorption from the small intestine. Others cause an increase in the faecal excretion of bile acids, an indirect route for elimination of cholesterol.

3. We have investigated the effects of different saponins on absorption of the bile salt sodium cholate from perfused loops of small intestine, in vivo, in the rat. Purified saponins from soapwort (Saponaria officinalis), soya beans and quillaia (Quillaia saponaria) reduced the rate of absorption of the bile salt; soya-bean and soapwort saponins substantially so but quillaia saponin to a much lesser extent.

4. These results were explained by the formation of large mixed micelles by bile acid and saponin molecules in aqueous solution. These aggregates can have molecular weights in excess of $10^{6}$ daltons, consequently the bile acid molecules incorporated in them are not available for absorption.

5. Control of plasma cholesterol and nutrient absorption through dietary saponins could provide substantial health and nutritional benefits in humans.

Saponins form a heterogeneous group of triterpene or steroid glycosides (Fig. 1) which occur in many hundreds of plant species (Tschesche \& Wulff, 1973). Many of these are staple items of the human diet (Oakenfull, 1981) and examples particularly rich in saponins are soya beans (Glycine max), chickpeas (Cicer arietinum), navy beans (Phaseolus vulgaris) and lucerne (Medicago sativa) (Fenwick \& Oakenfull, 1983). Isolated saponins and foods containing saponins have been shown to lower plasma cholesterol concentrations in a number of animal species (Malinow et al. 1977a; Oakenfull et al. 1979) and it has been suggested that foods containing saponins could be important in formulating hypocholesterolaemic diets for human consumption (Potter et al. 1980; Malinow et al. 1981). Thus the mechanism of the hypocholesterolaemic activity of saponins is of considerable interest.

Saponins remain within the gastrointestinal tract (Birk, 1969). Some interact directly with cholesterol producing an insoluble complex which prevents cholesterol absorption (Malinow et al. $1977 \mathrm{~b}$ ). Others appear to affect cholesterol metabolism indirectly by interacting with bile acids and increased faecal excretion of bile acids is observed in response to feeding saponins of this type (Oakenfull et al. 1979, 1984). Bile acids thus diverted from the enterohepatic cycle would be replaced by hepatic synthesis from cholesterol (Heaton, 1972).

We have shown that a commercial purified saponin from soapwort (Saponaria officinalis) forms large mixed micelles with bile acids. We measured rates of absorption of bile acids by perfused loops of small intestine in vivo (in the rat) and found that absorption from micellar solutions is greatly reduced compared with absorption from solutions containing no saponin (Oakenfull \& Sidhu, 1983). Thus, there may be a simple physico-chemical explanation for the effects of dietary saponins on cholesterol and bile acid metabolism. In the present paper we explore this possibility in more detail, using purified saponins from other plant sources. 


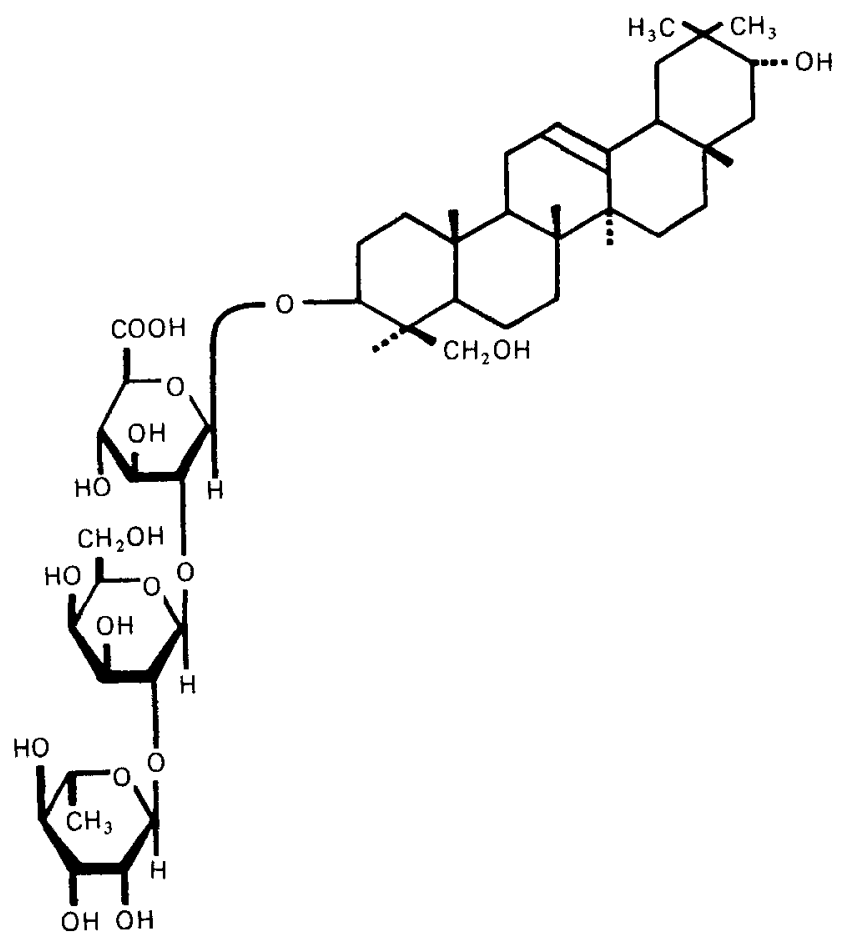

Fig. 1. Structure of a typical saponin (from soya beans Glycine max).

\section{MATERIALS AND METHODS \\ Saponins}

Quillaia saponin was a commercial extract from Quillaia saponaria (Keith Harris and Co. Ltd, Thornleigh, NSW), further purified by acetone precipitation from $n$-butanol solution and dried under vacuum. Soya-bean saponin was isolated from an ethanolic extract of soya-bean flour by a method based on that of Kitagawa et al. (1976).

\section{Absorption from loops of small intestine}

The animals were female Wistar rats, of mean body-weight 254 (SE 29) g, maintained on a commercial diet containing $230 \mathrm{~g}$ protein $/ \mathrm{kg}$ and $50 \mathrm{~g}$ crude fat $/ \mathrm{kg}$ (Allied Feeds, Rhodes, NSW). They were starved of food overnight and anaesthetized with intraperitoneal sodium pentobarbital $(60 \mathrm{mg} / \mathrm{kg}$ body-weight). The abdomen was opened by midline incision and the entire length of the jejunum and ileum divided into two sections, upper (U) and lower (L), of approximately equal length. Inflow cannulas were fitted and the lumen of each section was washed with isotonic saline $\left(9 \mathrm{~g}\right.$ sodium chloride/l) at $37^{\circ}$. Outflow cannulas were then fitted and the sections replaced inside the abdominal cavity which was closed using surgical clips. Isotonic solutions, pH 7.4 at $37^{\circ}$, were circulated separately through the lumen of each section at $2 \mathrm{ml} / \mathrm{min}$ for $50-60 \mathrm{~min}$. The solutions contained initially $3 \mathrm{~mm}$-sodium [carboxyl- ${ }^{14} \mathrm{C}$ ]cholate. Saponin was added when required at a concentration of $10 \mathrm{~g} / \mathrm{kg}$. CrEDTA was added to monitor absorption or loss of water. Samples $(0.1 \mathrm{ml})$ of the circulating solutions were taken at 5 -min intervals for measurement of ${ }^{14} \mathrm{C}$ radioactivity (Packard Tricarb 2660 scintillation counter). At the end of each experiment the sections of intestine were removed, washed in isotonic saline, laid on absorbent paper and their lengths measured. 
Table 1. Rates of absorption (pmol/s per mm length) of cholate from solutions circulated through loops of small intestine in vivo in the rat

(Means and standard errors are given)

\begin{tabular}{|c|c|c|c|c|c|c|c|}
\hline \multirow[b]{2}{*}{ Saponin } & \multirow{2}{*}{$\begin{array}{c}\text { No. } \\
\text { of } \\
\text { animals }\end{array}$} & \multicolumn{2}{|c|}{ Upper loop } & \multicolumn{2}{|c|}{ Lower loop } & \multicolumn{2}{|c|}{$\begin{array}{l}\text { Active } \\
\text { transport }\end{array}$} \\
\hline & & Mean & SE & Mean & SE & Mean & SE \\
\hline Control & 11 & $9 \cdot 0$ & 0.8 & $25 \cdot 3$ & $2 \cdot 3$ & 7.9 & $1 \cdot 2$ \\
\hline $\begin{array}{l}\text { Quillaia } \\
\text { (Quillaia saponaria) }\end{array}$ & 6 & $7 \cdot 9$ & $2 \cdot 0$ & $15 \cdot 9 * *$ & $1 \cdot 3$ & $4 \cdot 7^{*}$ & $1 \cdot 1$ \\
\hline $\begin{array}{l}\text { Soya bean } \\
\text { (Glycine max) }\end{array}$ & 5 & $5 \cdot 1^{*}$ & 0.9 & $8 \cdot 5^{* * *}$ & $1 \cdot 8$ & $1 \cdot 7^{* *}$ & $0 \cdot 8$ \\
\hline $\begin{array}{l}\text { Soapwort } \\
\text { (Saponaria officinalis) }\end{array}$ & 9 & $6 \cdot 0^{* *}$ & $1 \cdot 1$ & $11 \cdot 4^{* *}$ & $1 \cdot 0$ & $3 \cdot 5^{* *}$ & 0.7 \\
\hline
\end{tabular}

Mean values were significantly different from controls (paired $t$ test): ${ }^{*} P<0.05,{ }^{* *} P<0.01,{ }^{* * *} P<0.001$.

$\uparrow$ Included for comparison from Oakenfull \& Sidhu (1983).

$\ddagger$ Averaged over the entire length of the ileum plus jejunum.

\section{Diffusion through cellulose membranes}

Solutions $(50 \mathrm{ml})$ containing the same concentrations of saponin and cholate used in the experiments in vivo were sealed by means of knots into cellulose tubing of flat width $32 \mathrm{~mm}$. Each of these bags was then shaken with $50 \mathrm{ml}$ of isotonic buffer at 80 oscillations/min in a reciprocating water bath maintained at $37^{\circ}$. Samples $(0.1 \mathrm{ml})$ were taken from the external solution at 15 -min intervals for measurement of ${ }^{14} \mathrm{C}$ radioactivity. First-order rate-constants for the appearance of cholate in the external solution were calculated by the method of least squares from semi-logarithmic plots of radioactivity $v$. time. After allowing $24 \mathrm{~h}$ for equilibration the normal concentrations of cholate were measured on each side of the dialysis membrane. Since the micelles are too large to pass through, the external concentration gives the concentration of free cholate in equilibrium with the micelles - the effective concentration available for absorption. The external and internal concentrations combined give the stoichiometry of the mixed micelles.

\section{RESULTS}

Absorption of cholate from perfused loops of small intestine

The results obtained for intestinal absorption of sodium cholate are summarized in Table 1. Rates of absorption were consistently higher from lower loops than from upper loops since the lower loops contained the region of terminal ileum where there are sites for active transport of bile acids (Dietschy, 1968; Heaton, 1972). The contribution from active transport to absorption from lower loops was calculated by making the reasonable assumption that passive absorption is uniform along the entire length of the small intestine (Dietschy, 1968). The rate for the upper loop, where there is no active transport, can then be used to estimate the passive contribution to absorption from the lower loop and hence, by difference, the contribution from active transport.

We found that soya-bean saponin added to the circulating solutions at the same molar concentration as the bile acid substantially reduced both passive and active absorption of cholate (as did soapwort saponin). Quillaia saponin also lowered absorption rates but to a considerably lesser extent. 


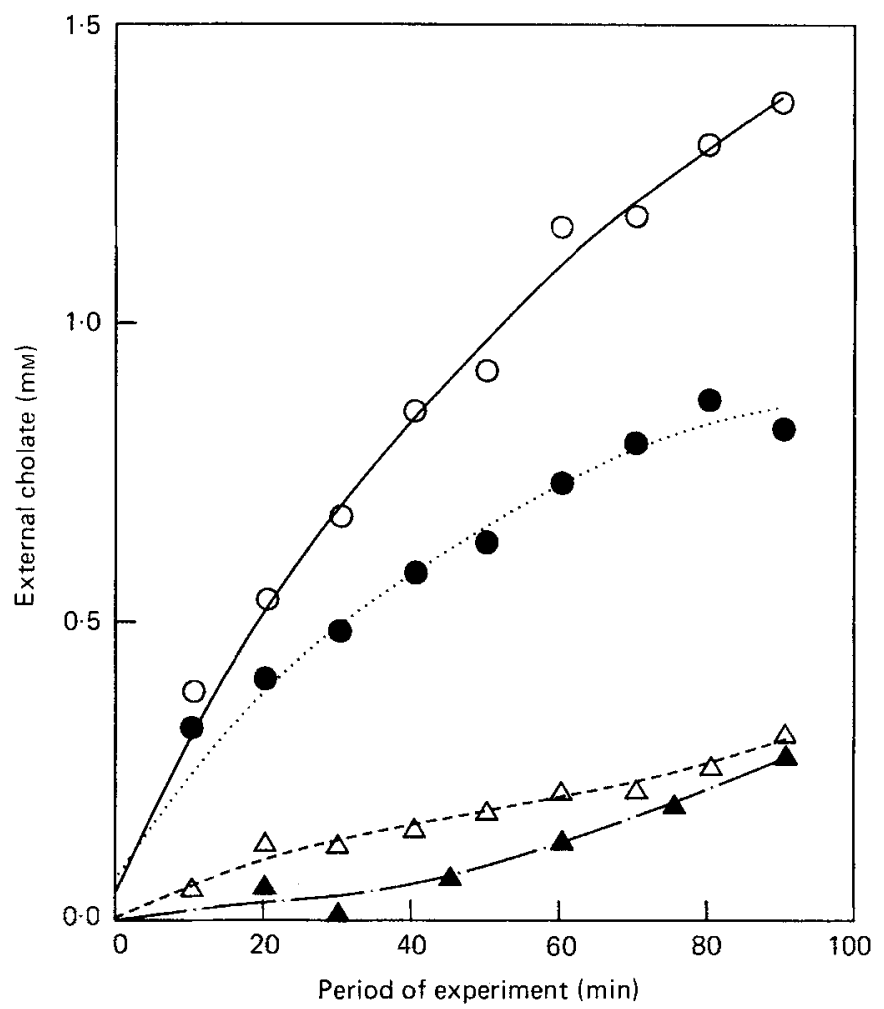

Fig. 2. Effects of saponins on diffusion of cholate through cellulose membranes at $37^{\circ}$ in vitro. The curves show the emergence of labelled cholate into an isotonic solution (external) from a dialysis bag containing an equal volume of the saponin solution (also isotonic). The concentration of saponin was $10 \mathrm{~g} / \mathrm{kg}$ and the initial concentration of cholate was $3 \mathrm{~mm}$. (O) Control, (O) quillaia (Quillaia saponaria) saponin, $(\triangle)$ soapwort (Saponaria officinalis) saponin, (A) soya-bean (Glycine max) saponin.

\section{Rates of diffusion in vitro}

The presence of saponins reduced the rate of passive diffusion of cholate through cellulose membranes as shown in Fig. 2. The saponins were again added at the same molar concentration as the cholate. The rate reduction was greatest for soya-bean saponin and soapwort saponin with only a small reduction caused by quillaia saponin.

\section{DISCUSSION}

Formation of mixed micelles by saponins and bile acids

Since much of this discussion hinges on the formation of mixed micelles by saponins and bile acids we start with a brief description of this process (full details are published elsewhere (Oakenfull, 1986)).

Saponins and bile acids are both amphiphilic compounds, partly hydrophobic, partly hydrophilic. In aqueous solution individually they form small micelles, their hydrophobic triterpene or steroid groups stacking together like small piles of coins (see Fig. 3). When the two types of compound are mixed their hydrophobic groups interleave with each other in their stacks (also shown in Fig. 3). The steric and electrostatic constraints to the formation of micelles are relieved and the stacks become greatly extended, incorporating many hundreds of molecules. 
(a)

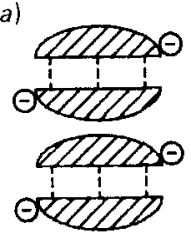

(b)

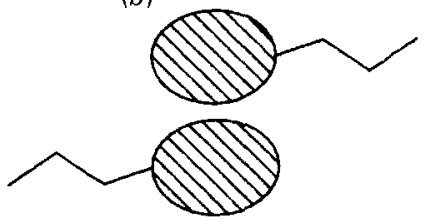

(c)
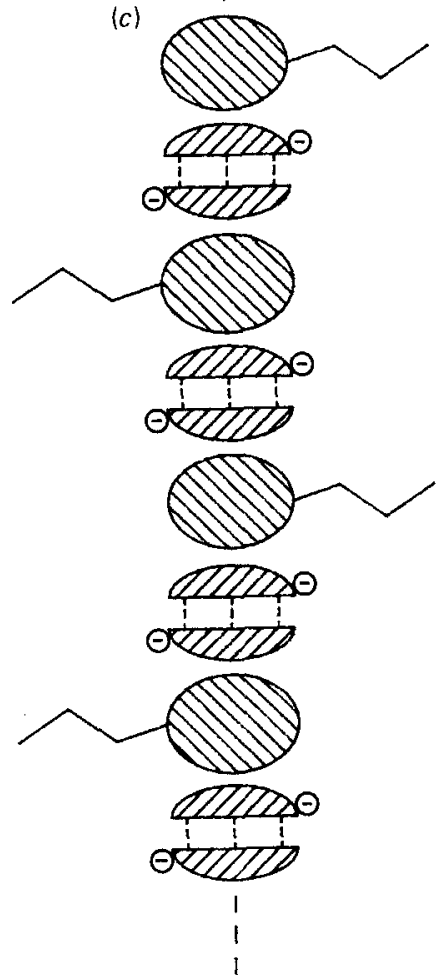

Fig. 3. Schematic diagram of the structures of the micelles formed by $(a)$ bile acids, $(b)$ saponins and (c) saponins plus bile acids. The hydrophobic triterpene group of the saponin is indicated by an ellipse; each monosaccharide group is indicated by a straight line.

Table 2. Some characteristics of the mixed micelles formed by saponins and cholate in isotonic buffer $(p H 7 \cdot 2)$ at $37^{\circ}$

\begin{tabular}{|c|c|c|c|c|}
\hline Saponin & $\begin{array}{l}\text { Molecular wt of } \\
\text { mixed micelle } \\
\text { (daltons) }\end{array}$ & $\begin{array}{l}\text { Micelle } \\
\text { shape }\end{array}$ & $\begin{array}{c}\text { Ratio } \\
\text { saponin: cholate } \\
\text { (molecules/micelle) }\end{array}$ & $\begin{array}{l}\text { Free cholate in } \\
\text { solutions containing } \\
10 \mathrm{~g} \text { saponin } / \mathrm{kg} \\
\text { and } 3 \mathrm{~mm}-\mathrm{total} \\
\text { cholate (mM) }\end{array}$ \\
\hline $\begin{array}{l}\text { Soapwort } \\
\text { (Saponaria officinalis) }\end{array}$ & $\sim 10^{6}$ & Filamentous & 7 & $1 \cdot 57$ \\
\hline $\begin{array}{l}\text { Quillaia } \\
\text { (Quillaia saponaria) }\end{array}$ & $\sim 10^{5}$ & Rod-like & 40 & $2 \cdot 74$ \\
\hline $\begin{array}{l}\text { Soya bean } \\
\text { (Glycine } \max \text { ) }\end{array}$ & $2 \times 10^{8}$ & Spherical & 8 & 1.79 \\
\hline
\end{tabular}




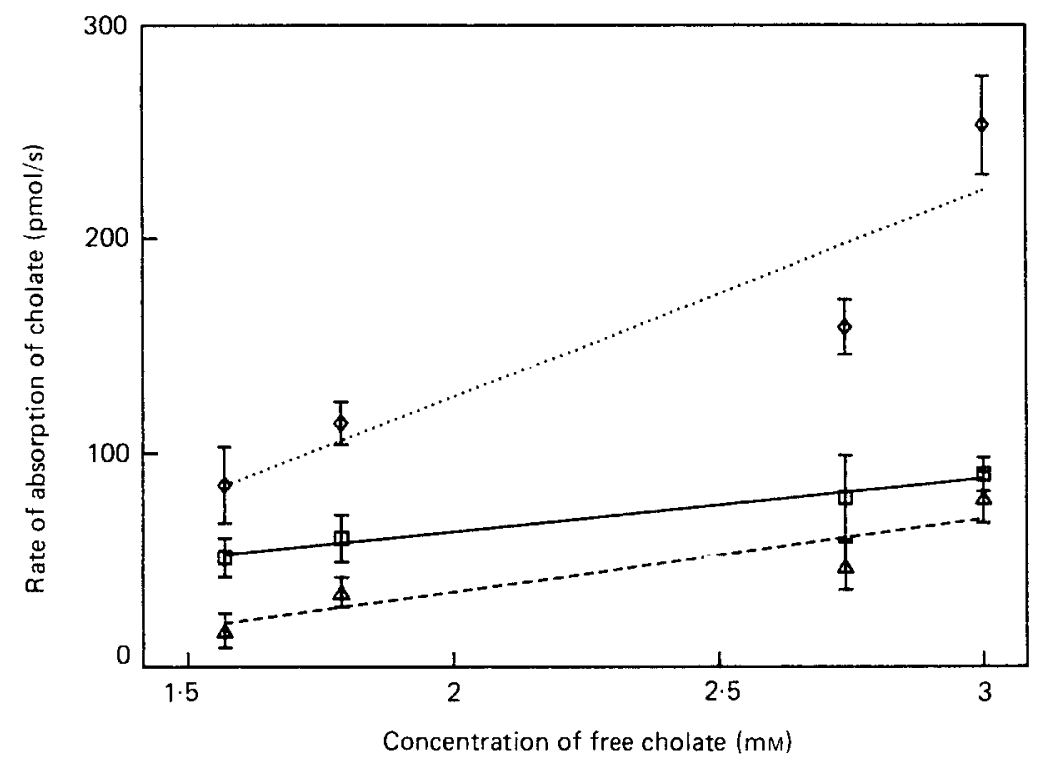

Fig. 4. Active transport and passive rates of absorption of cholate $v$. its estimated free concentration in the perfusate. $(\diamond \cdots \diamond)$ Lower loop, $(\square-\square)$ active transport, $\left(\triangle^{--} \triangle\right)$ upper loop (see p. 645 for details).

The sizes and detailed structures of these mixed micelles depend on the detailed chemical structure of the saponin molecules. Some characteristics of the mixed micelles formed by cholate and the three saponins we have investigated are summarized in Table 2 . The micelles formed by cholate and soapwort saponin or soya-bean saponin are very large but have different geometries. The micelles of quillaia saponin and cholate are much smaller but resemble those of saponin-white in structure. Some electron micrographs of these structures are shown in Plate 1.

All three types of micelle would be too large to pass through the gut wall (saponins, in any case, remain within the gastrointestinal tract (Birk, 1969)) so only free, non-micellar, cholate is available for absorption. Table 2 includes the concentrations of free cholate in solutions containing $3 \mathrm{~mm}$-cholate and $10 \mathrm{~g}$ saponin $/ \mathrm{kg}$ - the concentrations used for the measurements of rates of intestinal absorption. The free cholate concentration was substantially lowered by soapwort saponin and soya-bean saponin and this quantitatively explains the effects of these saponins on cholate absorption in vivo.

\section{Absorption of bile acids by the small intestine}

Bile acids are absorbed through the wall of the small intestine by passive diffusion and by active transport (Dietschy, 1968). Passive absorption takes place along the entire length of the ileum and jejunum; active transport is confined to the terminal ileum.

Saponins can interact with cell membranes, as is obvious from their haemolytic activity (Birk, 1969). Electron microscopy has revealed marked changes to cell membranes from erythrocytes and liver when exposed to saponins (Dourmashkin et al. 1962). Nuclear magnetic resonance studies have shown effects of saponin on the molecular organization within model-membrane systems prepared from phospholipid and cholesterol (Akiyama et al. 1980). Even more significantly, a saponin (digitonin) has been shown to increase the permeability to glucose of phospholipid vesicles (Nakamura et al. 1979).

Our results show that the effects of saponins on both passive absorption and active 
British Journal of Nutrition, Vol. 55, No. 3

Plate 1
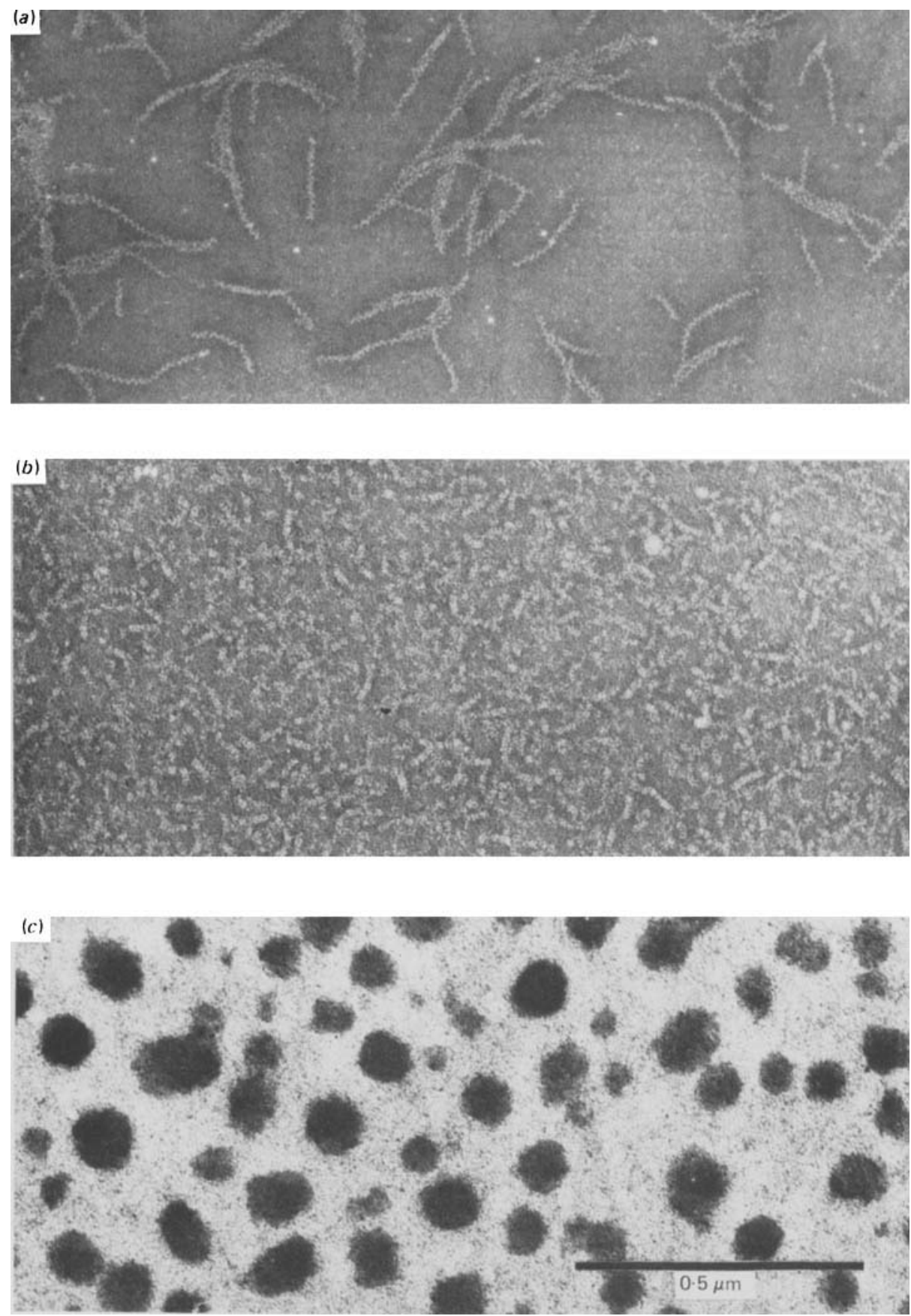
transport can be explained as simply due to the reduction in the concentration of free (as opposed to micellar) bile acid. The rates of passive absorption and active transport were both linearly related to the concentration of free cholate as shown in Fig. 4. There was no evidence for specific effects from the different saponins.

Low concentration of free bile acids seems to lower the efficiency of lipid absorption generally (Oakenfull et al. 1979) and presumably also affects absorption of fat-soluble vitamins. Another factor to be considered arises from the recent observation (West et al. 1984) that casein given to rabbits loses its hypocholesterolaemic effect when its hydrolysis and absorption by the intestine is modified by treatment with formaldehyde. Thus, change in rates and patterns of nutrient absorption could produce significant and sustained metabolic changes in the animal.

\section{CONCLUSIONS}

Formation of mixed micelles in the small intestine by certain saponins and bile acids provides a molecular explanation for the effects of saponins on bile acid and cholesterol metabolism. Micellar bile acid molecules are not available for reabsorption and are thus diverted from the enterohepatic cycle. Consequently ingestion of foods containing these saponins would increase faecal excretion of bile acids and could lower plasma cholesterol concentrations in hypercholesterolaemic subjects.

The authors are indebted to Dr R. W. Sleigh for obtaining the electron micrographs of saponins-bile acid mixed micelles.

\section{REFERENCES}

Akiyama, T., Takagi, S., Samkawa, U., Inari, S. \& Saito, H. (1980). Biochemistry 19, 1904-1911.

Birk, Y. (1969). In Toxic Constituents of Plant Foodstuffs, pp. 169-210 [I. E. Liener, editor]. New York: Academic Press.

Dietschy, J. M. (1968). Journal of Lipid Research 9, 297-309.

Dourmashkin, R. R., Dougherty, R. M. \& Harris, R. J. C. (1962). Nature 194, 1116-1119.

Fenwick, D. E. \& Oakenfull, D. (1983). Journal of the Science of Food and Agriculture 34, 186-191.

Heaton, K. W. (1972). Bile Salts in Health and Disease. Edinburgh: Churchill-Livingstone.

Kitagawa, I., Yoshikawa, M. \& Yosioka, I. (1976). Chemical and Pharmaceutical Bulletin 24, 121-129.

Malinow, M. R., Connor, W. E., McLaughlin, P., Stafford, C., Lin, D. S., Livingston, A. L., Kohler, G. O. \& McNulty, W. P. (1981). Journal of Clinical Investigation 67, 156-162.

Malinow, M. R., McLaughlin, P., Kohler, G. O. \& Livingston, A. L. (1977a). Steroids 29, 105-110.

Malinow, M. R., McLaughlin, P., Stafford, C., Livingston, A. L., Kohler, G. O. \& Cheeke, P. (1977b). American Journal of Clinical Nutrition 30, 2061-2067.

Nakamura, T., Inone, K., Najima, S., Sankawa, U., Shoji, T., Kawasaki, T. \& Shibata, S. (1979). Journal of Pharmacobio-Dynamics 2, 374-379.

Oakenfull, D. G. (1981). Food Chemistry 6, 19-40.

Oakenfull, D. G. (1986), Australian Journal of Chemistry (In the Press.)

Oakenfull, D. G., Fenwick, D. E., Hood, R. L., Topping, D. L., Illman, R. J. \& Storer, G. B. (1979). British Journal of Nutrition 42, $209-216$.

Oakenfull, D. G. \& Sidhu, G. S. (1983). Nutrition Reports International 27, 1253-1259.

Oakenfull, D. G., Topping, D. L., Illman, R. J. \& Fenwick, D. E. (1984). Nutrition Reports International 29, 1039-1046.

Potter, J. D., Illman, R. J., Calvert, G. D., Oakenfull, D. G. \& Topping, D. L. (1980). Nutrition Reports International 22, 521-528.

Tschesche, von R. \& Wulf, G. (1973). In Progress in the Chemistry of Organic Natural Products, pp. 461-606 [W. Hertz, H. Grisebach and G. W. Kirby, editors]. Vienna: Springer-Verlag.

West, C. E., Beynen, A. C., Scholz, K. E., Terpstra, A. H. M., Schutte, J. B., Deuring, K. \& van Gils, L. G. M. (1984). Journal of Nutrition 114, 17-25.

EXPLANATION OF PLATE

Plate 1. Electron micrographs of mixed micelles of cholate and saponin. (a) Soapwort (Saponaria officinalis) saponin, $(b)$ quillaia (Quillaia saponaria) saponin, (c) soya-bean (Glycine max) saponin. (Images were obtained by negative staining using bacitracin and potassium phosphotungstate.) 